\title{
Band-Notched Ultra-Wideband Antenna with Asymmetric Coupled-Line for WLAN and X-Band Military Satellite
}

\author{
Jun-Hyuk Lee • Young-Je Sung
}

\begin{abstract}
This paper presents a novel ultra-wideband (UWB) antenna that rejects narrow and broad bands and is suitable for wireless communications. The base of the proposed antenna has a circular patch that can cover the UWB frequency range $(3.1 \sim 10.6 \mathrm{GHz})$. The interference issues caused by co-existence within the UWB operation frequency are overcome by a design that uses a parallel-coupled asymmetric dual-line with a circular monopole antenna. The proposed antenna showed a stable radiation pattern, realized gain and reflection coefficient lower than $-10 \mathrm{~dB}$ across the UWB operation bandwidth except for $5.15 \sim 5.85 \mathrm{GHz}$ and $7.25 \sim 8.4 \mathrm{GHz}$. The fabrication, simulation, and measurement results obtained for the proposed antenna were in good agreement with the expected values.
\end{abstract}

Key words: Parallel Coupled Line, Notch-Bands, Patch Antenna, Ultra-Wideband (UWB).

\section{I . Introduction}

The allocation by the Federal Communication Commission (FCC) of the unlicensed band at frequencies between $3.1 \sim 10.6 \mathrm{GHz}$ [1] for commercial purposes has resulted in rapid development of ultra-wideband (UWB) wireless communication systems. This frequency band is now in great demand in microwave components such as indoor and hand-held wireless devices, owing to its merits, particularly its good impedance matching, large bandwidth, low signal distortion and high speed of more than $100 \mathrm{Mbps}$ within the operation frequency bands [2]. However, a problem arises that affects and interrupted UWB operation. For example, UWB systems will experience interference from the wireless communication bands of Wireless Local Area Network (WLAN) $(5.15 \sim 5.35 \mathrm{GHz}$ \& $5.725 \sim 5.825 \mathrm{GHz})$ and X-band military satellite $(7.25$ $\sim 7.75 \mathrm{GHz} \& 7.9 \sim 8.4 \mathrm{GHz}$ ). Therefore, the bands used fort WLAN and X-bands military satellite must be rejected. UWB researchers have attempted to suppress this interference by studying and investigating various band stop methods that reject the typical WLAN band or large part of it [3] [6]. One of the methods used to suppress some interference frequencies adapt a parallel coupled line and this can demonstrate notch characteristics [7], [8].
This paper describes a UWB monopole antenna with band-stop characteristics that uses a parallel-coupled dual-line. The asymmetric dual-line is suggested. The proposed antenna can suppress interference from strong narrow and broad by controlling the asymmetric dual-line. However, this solution can only reject planned interference bands. The operation characteristics in UWB, which eliminates influences related to WLAN and X-band military satellite, are advanced by determining and optimizing the proposed antenna by a parasitic line in a parallel-coupled line. Additionally, to achieve the good impedance matching, the bottom GND of the proposed antenna is modified by cutting rectangular slot on the center edge and symmetrical rectangular slots on the right and left edge [9]. These adaptations allowed the optimal design, fabrication, and measurement of a UWB notch antenna with an asymmetric dual-line.

\section{II . Antenna Geometry}

The configuration of the UWB printed antenna for band-notch characteristics is proposed in Fig. 1(a) and (b). The proposed antenna consists of a circular patch radiator and a parallel-coupled asymmetric dual-line on a Taconic substrate with a size of $53 \mathrm{~mm} \times 40 \mathrm{~mm}$, thickness of $1.14 \mathrm{~mm}$, and relative permittivity 2.2 . The

Manuscript received December 27, 2012 ; Revised January 31, 2013 ; Accepted February 14, 2013. (ID No. 20121227-031J)

Dept. of Electronic Engineering, Kyonggi University, Suwon, Korea.

Corresponding Author : Young-Je Sung (e-mail : yjsung@kgu.ac.kr)

This is an Open-Access article distributed under the terms of the Creative Commons Attribution Non-Commercial License (http:/creativecommons.org/licenses/ by-nc/3.0) which permits unrestricted non-commercial use, distribution, and reproduction in any medium, provided the original work is properly cited. 


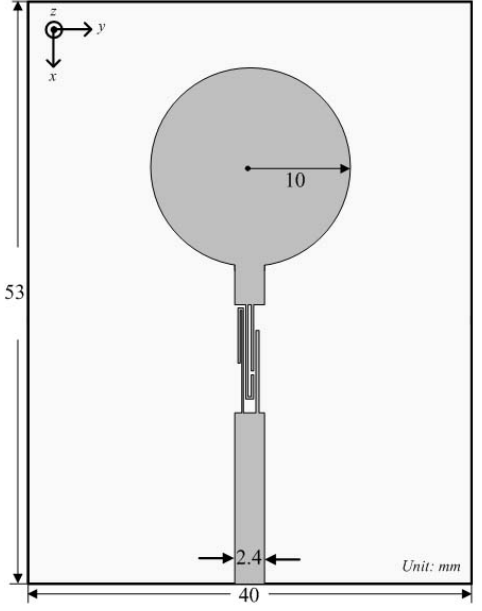

(a)

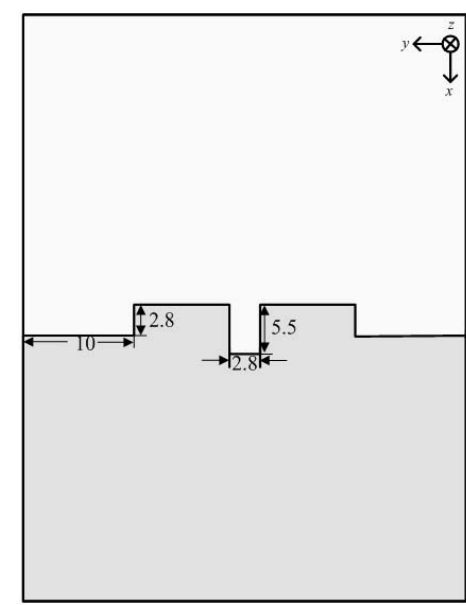

(b)

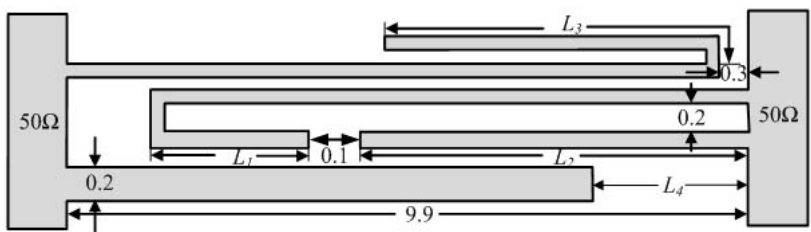

(c)

Fig. 1. (a) Top layer, (b) bottom layer, (c) topogoly of the proposed asymmetric notch design.

adopted circular patch is operated as a radiating function and the microstrip feed line is fixed at $2.4 \mathrm{~mm}$ to activate $50-\Omega$ characteristic impedance at $3.1 \sim 10.6 \mathrm{GHz}$. The detailed parallel-coupled asymmetric dual-line of the proposed antenna is shown in Fig. 1(c). Based on these points, the parameters are as follows: the parameters follow as: $L_{1}=2.2 \mathrm{~mm}, L_{2}=6.3 \mathrm{~mm}, L_{3}=5 \mathrm{~mm}, L_{4}=2.3 \mathrm{~mm}$. The gap between the strips in the parallel-coupled strips in parallel-coupled line is $0.1 \mathrm{~mm}$ except for the $0.2 \mathrm{~mm}$ previously mentioned. This interdigital coupled-line structure generates a higher current density and phase transit so that it can activate a notched band under the operation

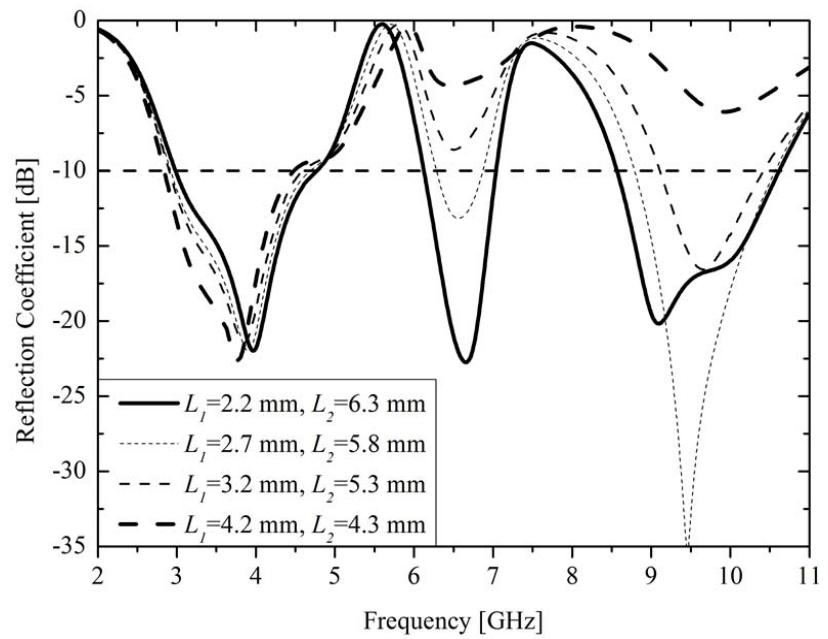

Fig. 2. Comparisons of simulated reflection coefficient for various lengths $L_{1}$ and $L_{2}$ in asymmetric coupledline.

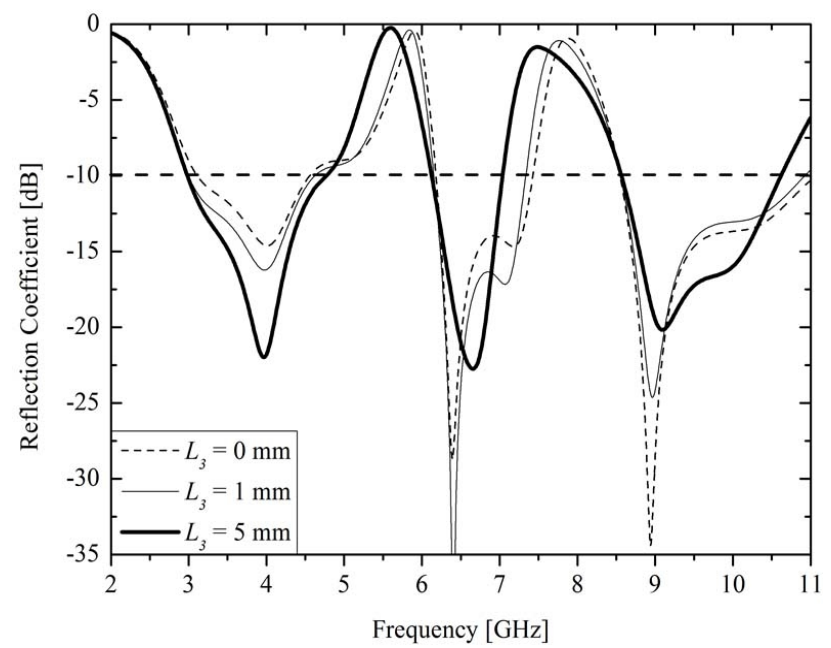

(a) $L_{3}$

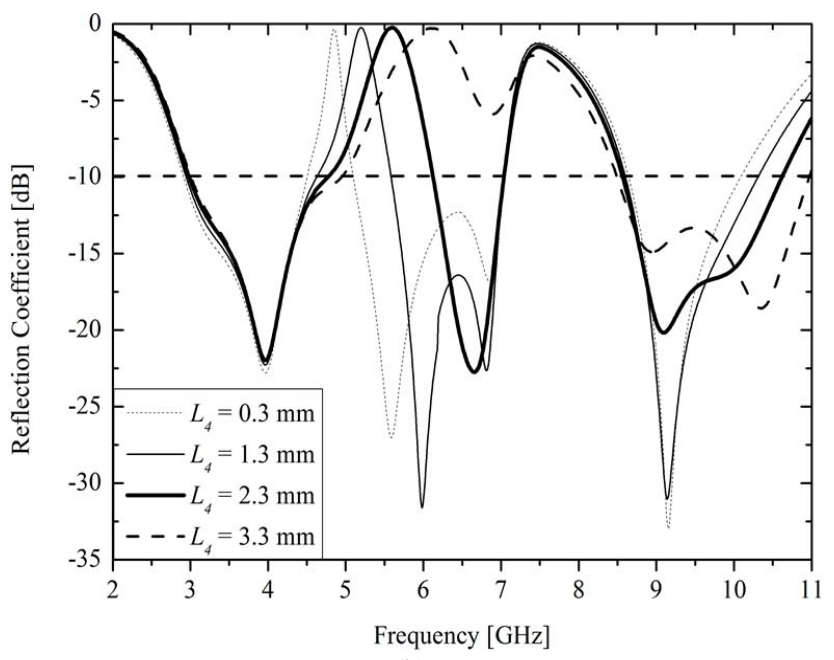

(b) $L_{4}$

Fig. 3. Comparisons of simulated reflection coefficients for various lengths 
passband [10]. The reason for forming a cut-off frequency is so that the parallel coupled-line structure can achieve high tight coupling [11]. The band-notch bandwidths can be controlled by parameter analysis with the length $L_{1}$ and $L_{2}$ in a parallel-coupled dual-line. When the values of $L_{1}$ and $L_{2}$ differ, this can be used as a cut-off characteristic for the two different frequency bands. In contrast, when the values of $L_{1}$ and $L_{2}$ is are identical, the band-notched effect occurs at one frequency band. As shown in Fig. 2, the asymmetric dual-line is also available to reject the two band-notches by controlling $L_{1}$ and $L_{2}$. The proposed antenna also takes into consideration that parasitic line $L_{3}$ and $L_{4}$ are suitable for shifting to suppress the specified frequency WLAN and X-band military satellite bands independently. The simulated frequency responses of the parametric analysis with $L_{3}$ and $L_{4}$ are depicted in Fig. 3(a) and (b). Consequently, the higher band (X-band military satellite band) shifts to low when $L_{3}$ is increased. Conversely, the lower band (WLAN) moves to high when $L_{4}$ is increased.

\section{Simulated and Measured Results}

The proposed UWB antenna is simulated using electro-magnetic simulation tools HFSS and measured using Wiltron 3605B network analyzer at the frequency from $2 \mathrm{GHz}$ to $11 \mathrm{GHz}$. By adopting the methods of a different length for $L_{1}$ and $L_{2}$ and tuning the parasitic length $L_{3}$ and $L_{4}$, the WLAN and X-band military satellite bands are bypassed. Fig. 4 shows the simulated and measured reflection coefficient $(\mathrm{dB})$ with and without the asymmetric dual-line $\left(S_{11}<-10 \mathrm{~dB}\right)$. The result is somewhat different between the simulated and measured value, which shifts to and upper frequency about $20 \mathrm{MHz}$. These results satisfy the planned bandwidth with only a slight error in measurement. The simulated and measured radiation patterns are shown as E-plane and $\mathrm{H}$ -

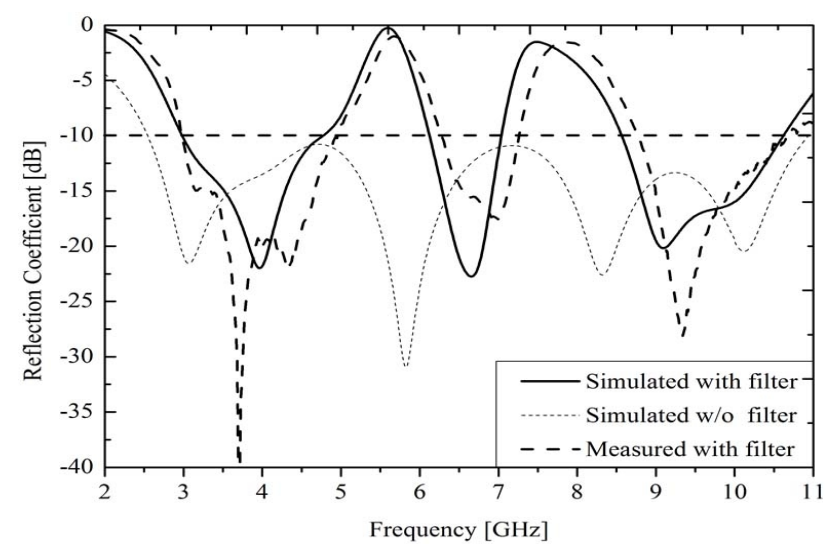

Fig. 4. Simulated and measured reflection coefficient $(\mathrm{dB})$ with and without a notch coupled-line.

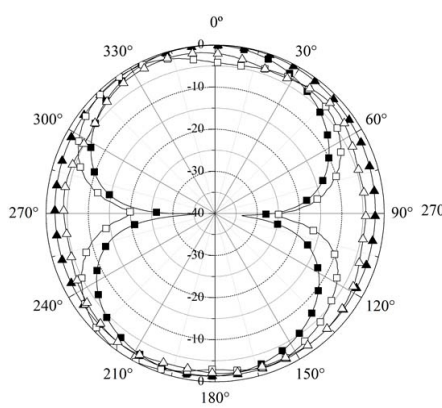

(a) $3.1 \mathrm{GHz}$

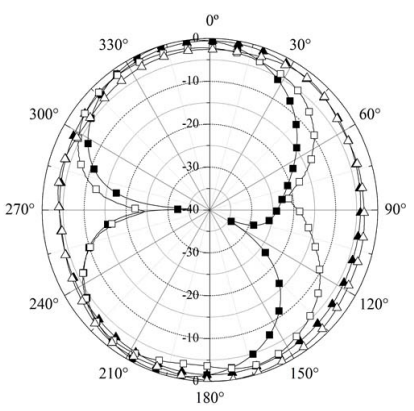

(b) $4 \mathrm{GHz}$

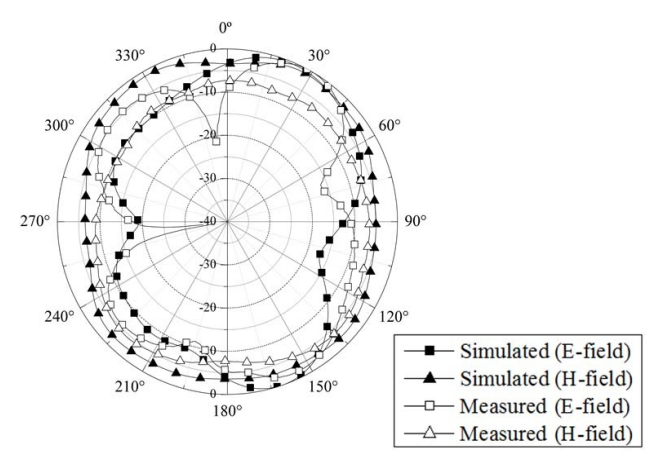

(c) $9 \mathrm{GHz}$

Fig. 5. Simulated and measured 2D radiation patterns of proposed antenna.

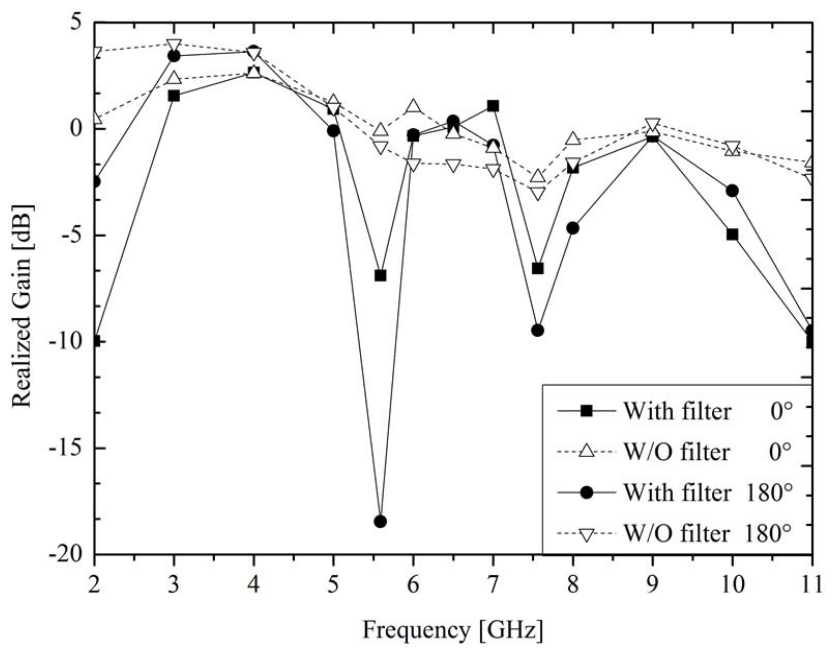

Fig. 6. Realized gain $(\mathrm{dB})$ of the proposed antenna.

plane in Fig. 5(b) and (c). The proposed fabrication has dipole-like stable and omnidirectional radiation patterns across all the operation bands. Finally, the realized gain is shown for the simulated result at two angles $0^{\circ}$ and $180^{\circ}$ in Fig. 6. Consequently, a rapid decrease occurs at notch frequencies when the band-notched dual-line is added at $0^{\circ}$ and $180^{\circ}$.

\section{Conclusion}

This work proposes a shorted monopole antenna with 
a coupled UWB antenna with asymmetric dual-line for notch characteristics has been proposed. We adapted an asymmetric dual-line and confirmed the rejection of narrow and broad bands $(5.15 \sim 5.85 \mathrm{GHz} \& 7.25 \sim 8.4 \mathrm{GHz})$. The band-notch frequencies are tuned by adjusting reasonable values through parameter analysis. The results obtained using the proposed antenna have been promising, and hence, this antenna appears to be suitable for use in UWB communication systems.

This work was supported by Kyonggi University Research Assistant Fellowship 2012.

\section{References}

[1] Fed. Commun. Comm, "First report and order, revision of part 15 of the commission's rule regarding ultra-wide band transmission systems," FCC 02-48, Apr. 2002.

[2] I. Oppermann, M. Hamalainen, and J. Iinatti, UWB Theory and Applications, New York: Wiley, ch. 1, pp. 3-4, 2004.

[3] Lin Peng, Cheng-Li Ruan, "UWB band-notched monopole antenna design using electromagnet- bandgap structures," IEEE Trans. on Microw. Theory and Techniques, vol. 59, no. 4, pp. 1074-1081, Apr. 2011.

[4] Sung-Jung Wu, Cheng-Hung Kang, Keng-Hsien Chen, and Jenn-Hwan Tarng, "Study of an ultra wideband monopole antenna with a band-notched open looped resonator," IEEE Trans. Antennas. Propag., vol. 58,

Jun-Hyuk Lee

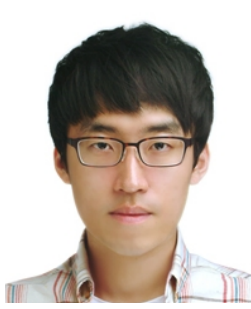

was born in Seoul, Korea, in 1986. He received the B.S. in 2012. Since 2011, he has studied and researched RF subject at Microwave Lab., Kyonggi University, Suwon, Korea. His research interests include reconfigurable antennas, cellphone antennas, wideband and compact UWB antenna. no. 6, pp. 1890-1897, Jun. 2010.

[5] J. Liu, S. Gong, Y. Xu, X. Zhang, C. Feng and N. Qi, "Compact printed ultra-wideband monopole antenna with dual band-notched characteristics," Electron. Lett., vol. 44, no. 12, pp. 710-711, Jun. 2008.

[6] Chao Yu, Wei Hong, Leung Chiu, Guohua Zhai, Chen $\mathrm{Yu}$, Wei Qin, and Zhenqi Kuai, "Ultrawideband printed log-periodic dipole antenna with multiple notched bands," IEEE Trans, Antennas, Propag., vol. 59, no. 3, pp. 725-732, Mar. 2011.

[7] Hussein Shaman, Jia-Sheng Hong, "Asymmetric parallel-coupled lines for notch implementation in UWB filters," IEEE Microw. and Wirel. Compon. Lett., vol. 17, no. 7, pp. 516-518, Jul. 2007.

[8] K. Song, Q. Xue, "Asymmetric dual-line coupling structure for multiple-notch implementation in UWB bandpass filters," Electron. Lett., vol. 46, no. 20, pp. 1388-1390, Sep. 2010.

[9] R. Azim, M. T. Islam, and N. Misran, "Ground modified double-sided printed compact UWB antenna," Electron. Lett., vol. 47, no. 1, pp. 9-11, Jan. 2011.

[10] Sheng Sun, Lei Zhu, "Capacitive-ended interdigital coupled lines for UWB bandpass filters with improved out-of-band performances," IEEE Microw. and Wirel. Compon. Lett., vol. 16, no. 8, pp. 440-442, Aug. 2006.

[11] K. Song, Y. Fan, "Compact ultra-wideband bandpass filter using dual-line coupling structure," IEEE Microw. Wirel. Compon. Lett., vol. 19, no. 1, pp. 3032, Jan. 2009.

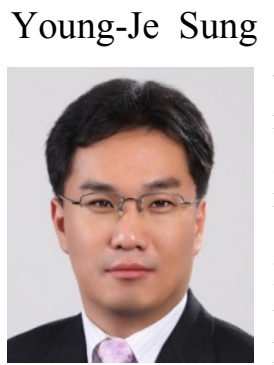

was born in Incheon, Korea, in 1975. He received the B.S., M.S., and Ph.D. degrees from Korea University, Seoul, Korea, in 2001, 2002, and 2005, respectively. From 2005 to 2008 , he was a Senior Engineer with the Antenna R\&D Laboratory, Samsung Electronics, Korea. In 2008, he joined the Department of Electronic Engineering, Kyonggi University, Suwon, Korea, where he is currently an Associate Professor. His research interests include reconfigurable antennas, cellphone antennas, wideband slot antennas, multifunction devices, compact circular polarized antennas, and compact dual-mode filters. Prof. Sung is serving as a reviewer for the IEEE Transactions on Microwave Theory and Techniques, IEEE Microwave and Wireless Components Letters, IEEE Antennas And Wireless Propagation Letters, Progress in Electromagnetic Research, IET Electronics Letters, IET Microwaves, Antennas and Propagation, and the ETRI Journal of the Electronics and Telecommunications Research Institute, Korea. 